\title{
An Evaluation of an Animal Model of Cerebral Palsy: The Effects on the Morphology of the Extensor Digitorum Longus Muscle
}

\author{
Evaluación de un Modelo Animal de Parálisis Cerebral: Los Efectos \\ sobre la Morfología del Músculo Extensor Largo de los Dedos
}

Covatti, C. ${ }^{\text {; }}$ Ulsenheimer, B. H. ${ }^{\text {' }}$ Buratti, P. ${ }^{1}$; Centenaro, L. A. ${ }^{2}$; Guimarães, A. T. B. ${ }^{3}$ Brancalhão, R. M. C. ${ }^{3}$ \& Torrejais, M. M. ${ }^{3}$

COVATTI, C.; UlSENHEIMER, B. H.; BURATti, P.; CENTENARO, L. A.; GUIMARÃES, A. T. B.; BRANCALHÃO, R. M. C. \& TORREJAIS, M. M. An evaluation of an animal model of cerebral palsy: The effects on the morphology of the extensor digitorum longus muscle. Int. J. Morphol., 36(3):886-894, 2018.

SUMMARY: Cerebral Palsy (CP) refers to chronic childhood encephalopathy. The objective of this study was to verify effects of CP model that combines prenatal exposure to LPS, perinatal anoxia and sensorimotor restriction on EDL muscle. Male Wistar rat pups were separated: a) Control - pups of mothers injected with saline during pregnancy and b) Cerebral Palsy - pups of mothers injected with LPS during pregnancy, and submitted to perinatal anoxia and sensorimotor restriction. The $\mathrm{CP}$ group presented hypertrophy in the type IIB fibers and increase of nuclei/fiber and capillary/fiber ratios. The intrafusal fibers of CP group presented $26 \%$ atrophy in the crosssectional area and intramuscular collagen volume increase $34 \%$. CP group showed myofibrillar disruption and Z-line disorganization and the NMJs presented increases of $22 \%$ in area.This animal model of CP produces motor deficits and macro and microscopic alterations and in the ultrastructure of the EDL muscle.

KEY WORDS: Cerebral Palsy; Rat; Extensor digitorum longus muscle; Morphology; Morphometry.

\section{INTRODUCTION}

Cerebral palsy $(\mathrm{CP})$ is defined as a chronic encephalopathy that causes sensorimotor disorders at different degrees of severity (Rotta, 2002), and is considered the most common cause of physical deficiency in childhood (Mancini et al., 2002). CP is believed to result from the interaction of multiple pre, peri, or postnatal risk factors (Bax et al., 2005). The musculoskeletal changes observed in these patients are mainly due to deficits in the execution of spontaneous movements and include atrophy or hypertrophy of the muscular fibers, increased volumes of connectivetissue in the musculature, bone malformation and degeneration of the articular cartilage (Coq et al., 2008).

Animal models are being developed with the purpose of reproducing the signs, symptoms and brain and musculoskeletal characteristics found in CP patients (Kerr Graham \& Selber, 2003). Inducing an animal CP model that combines prenatal exposure of rats to lipopolysaccharide (LPS), perinatal anoxia and post-natal sensorimotor restriction produced muscular atrophy in the anterior tibialis and soleus muscles, the transition from type I to type II fibers and changes in the motor skills of the animals (Stigger $e t$ al., 2011). In this experimental model, sensorimotor restriction is believed to mimic spasticity-induced immobility, while LPS and perinatal anoxia may mimic neuropathological findings in CP. However, a broad characterization of the muscular deficits produced by this animal model of CP in muscles in which type II fibers predominate, such as the extensor digitorum longus (EDL), has not yet been conducted. Therefore, the objective of this study was to investigate the effects of the combination of prenatal injections of LPS, perinatal anoxia and post-natal sensorimotor restriction on muscle fibers and NMJs in the EDL muscle in rat pups.

\footnotetext{
${ }^{1}$ Discente do Programa de Pós Graduação - Mestrado em Biociências e Saúde, Universidade Estadual do Oeste do Paraná, Cascavel, Brasil.

${ }^{2}$ Docente do Laboratório Experimental de Morfologia (LABEM), Universidade Estadual do Oeste do Paraná, Cascavel, Brasil.

${ }^{3}$ Docente do Programa de Pós Graduação - Mestrado em Biociências e Saúde, Universidade Estadual do Oeste do Paraná, Cascavel, Brasil. Financial support for the research: Coordination of Improvement of Higher Education Personnel (CAPES).
} 
COVATTI, C.; ULSENHEIMER, B. H.; BURATTI, P.; CENTENARO, L. A.; GUIMARÃES, A. T. B.; BRANCALHÃO, R. M. C. \& TORREJAIS, M. M. An evaluation of an animal model of cerebral palsy: The effects on the morphology of the extensor digitorum longus muscle. Int. J. Morphol., 36(3):886-894, 2018.

\section{MATERIAL AND METHOD}

Place, animals and induction of the animal model of CP. This research was approved by the Ethics in the Use of Animals Committee (CEUA - n² 24/16) of UNIOESTE. At the beginning of the experimental protocol, adult Wistar rats (42 females and 10 males), approximately three months old, from the UNIOESTE Central Bioterium (Animal Facility) were used. These animals were housed in polycarbonate boxes $(27 \times 26 \times 31 \mathrm{~cm})$ covered wood shavings, in an environment with a $12 \mathrm{~h} \mathrm{light/dark}$ cycle, controlled temperature $\left(20 \pm 2{ }^{\circ} \mathrm{C}\right)$, with water and food ad libitum.

Pregnancy was confirmed through the presence of spermatozoa to colpocytological examination. Then, some of the females were injected intraperitoneally with vehicle $(\mathrm{n}=15 ; 100 \mathrm{ml}$ of sterile saline); and the others with LPS $(\mathrm{n}=27$; approximately $200 \mathrm{mg} / \mathrm{kg}$ LPS in $100 \mathrm{ml}$ of sterile saline). Both injections were performed every $12 \mathrm{~h} \mathrm{(07:30}$ and 19:30 h), as from the 17th gestational day (G17) until the end of gestation (G21).

The day of birth of the offspring was considered the postnatal day $0(\mathrm{P} 0)$, when the pups were separated into two groups: 1) the Control group - pups of rats injected with saline during pregnancy (CTL, $\mathrm{n}=10)$ and 2$)$ the $\mathrm{CP}$ group - pups of rats injected with LPS during pregnancy, submitted to perinatal anoxia and sensorimotor restriction $(\mathrm{CP}, \mathrm{n}=10)$. Only male offspring were used in this study.

The offspring from the $\mathrm{CP}$ group underwent perinatal anoxia on P0. For this intervention, the pups were placed in a closed chamber, partially immersed in water at $37^{\circ} \mathrm{C}$, with a flow of $9 \mathrm{~L} / \mathrm{min}$ of nitrogen $(100 \%)$ for $20 \mathrm{~min}$. Following this procedure, the animals were quickly removed, kept under normal atmospheric conditions and observed until their normal respiratory pattern returned. The male offspring from the CTL group were also placed in the same chamber for 20 min, which remained open and with normal atmospheric airflow.

Finally, the pups from the $\mathrm{CP}$ group underwent sensorimotor restriction $16 \mathrm{~h} /$ day, from the first postnatal day (P1) to P30. Restriction was achieved with the aid of adhesive microporous tape and an epoxy mold (adjusted according to the size of the animal), which allowed the hind limbs to be immobilized in an extended position.

Evaluating the displacement time in the open field. The locomotor activity and exploratory behavior of the animals were evaluated on P29 and P45. The test apparatus, consisted of an arena $(40 \times 100 \times 100 \mathrm{~cm})$ with the floor subdivided into 12 squares. For each test, the animals were initially positioned in the northeast corner of the arena and removed after a period of five minutes. Each evaluation was filmed from above for later evaluation of the following parameters: number of line quadrants crossed, number of rearings, grooming frequency, total time immobile and total time mobile.

Sample collection. At 48 days of age, the animals from both groups were weighed and anesthetized with an overdose of ketamine hydrochloride $(50 \mathrm{mg} / \mathrm{kg}$, ip; Cristália, Brazil) and xylazine hydrochloride (10 mg/kg, ip; Cristália, Brazil). A dissection of the EDL muscle bilaterally was performed. The EDL muscle from the right antimere was then weighed and its length (muscular belly) measured using a digital caliper (Digimess, São Paulo, Brazil). The muscles were sectioned using a stainless steel blade and prepared for histological, histoenzymological and histochemical examination.

The histological and histoenzymological study of the muscle fibers and quantification of intramuscular collagen. After dissection, the proximal portions of the right antimere EDL muscle were maintained at room temperature for 30 to $40 \mathrm{~min}$. After which, the samples were covered with neutral talc (JOHNSON'S, São Paulo, Brazil) and frozen in liquid nitrogen for storage in a Biofreezer at $-80{ }^{\circ} \mathrm{C}$. Subsequently, cross sections ( $7 \mathrm{~mm}$ thick) of these samples were obtained using a cryostat (LUPETEC CM 2850 Cryostat Microtome).

Some of the sections obtained were stained using the Hematoxylin-Eosin (HE) technique. To quantify the nuclei, muscle fibers and capillary/fiber ratio, 10 images of randomized visual fields were used per animal (magnification of 400X). When measuring the capillary/fiber ratio, muscle fibers overlapping the upper and right margins were included in the count, while those overlapping the lower and left margin were excluded. Two trained evaluators individually performed the quantification and the mean values obtained were used. For the muscle spindle measurements, images (magnification of 1000X) of the same muscle spindle were captured in 10 different cuts per animal. Standardized measurements were made of the area and diameter of the muscle spindle, mean cross-sectional area of intrafusal fibers, number of intrafusal fibers and thickness of the spindle capsule in the muscle spindle with the largest diameter.

Some of the other the histological sections of the EDL muscle was submitted to NADH-TR (Nicotinamide Adenine Dinucleotide - Tetrazolium Reductase) reaction to analyze the oxidative and glycolytic metabolism of the muscle fibers. Images of two visual fields (200x magnification) were used for the morphometric analyzes (cross-sectional area and 
counts of the three types of muscle fibers) of approximately 300 fibers per animal.

To quantify the percentage of intramuscular collagen, the remainder of the histological sections of the EDL muscle was stained with Masson's Trichrome. Three microscopic images from each animal were used in the analysis (magnification 200X). Once the images were captured, the percentage of collagen/total area was calculated.

Transmission electron microscopy (T.E.M.) study. To visualize the ultrastructure of the muscle fibers from the EDL, the distal portions of the right antimere EDL was removed and reduced to longitudinal fragments (approximately one $\mathrm{mm}$ wide) and immersed in glutaraldehyde $(2.5 \%)$ for fixation. Subsequently, the samples were washed in $0.1 \mathrm{M}$ phosphate buffer, $\mathrm{pH} 7.3(15 \mathrm{~min})$ and post-fixed in $1 \%$ osmium tetroxide for two hours. After which, they were washed in distilled water, incubated in $0.5 \%$ uranyl acetate for $2 \mathrm{~h}$, dehydrated in acetone and soaked in a mixture of resin and $100 \%$ acetone ( $12 \mathrm{~h}$ ) for the subsequent formation of blocks. The desired fields were selected from semi-thin sections and ultra-thin sections were obtained using an ultramicrotome (Ultracut UCT, Leica, Germany). The ultrathin sections were stained with a saturated solution of uranyl acetate and lead citrate. The material obtained was examined and photographed in a transmission electron microscope (CM100, Philips, The Netherlands).

Evaluation of the NMJs. For the study of the NMJs, the proximal part of the left antimere of the EDL muscle was removed and immersed in Karnovsky at room temperature. Subsequently, the muscle was sectioned longitudinally into three or four slices with stainless steel blades for the nonspecific esterase reaction. Images of the NMJs (magnification of 200x) were obtained and measurements of the area and largest and smallest diameters of 100 NMJs were taken for each animal.

Image analysis. Images of the histological sections stained with HE, Masson's Trichrome staining and photodocumentation of the NMJs were taken using an Olympus
Bx60 microscope coupled to an Olympus DP17 camera (Tokyo, Japan) with the aid of the DP Controller 3.2.1 276 program. Morphometric analyzes were performed using Image Pro Plus 6.0 software (Media Cybernetics, Maryland, USA). The analysis of the cross-sectional area and counts of the three types of muscle fibers (NADH-TR reaction) was conducted on a Primo Star, Zeiss (Oberkochen, Germany) microscope coupled to a camera (AxiocamERc5s) and a computer, measurements were performed with the aid of Axiovision Rel. 4.8 software (Carl Zeiss Microimaging Inc., Germany).

Statistical analysis. The data obtained were statistically analyzed considering the results of the normality tests. Student's t-test was used when the data distribution was normal. In cases where the data distribution was not normal, the non-parametric Mann-Whitney statistical test was used. For the NADH-TR analysis, the two-way ANOVA test was used using the factors $\mathrm{CP}$ induction of and muscle fiber type, followed by Bonferroni's post-hoc test. Values of $p$ $<0.05$ were considered significant. The statistical analysis was performed with the aid of GraphPad Prism 5.0 software (La Jolla, USA).

\section{RESULTS}

Locomotor performance. The animals from the $\mathrm{CP}$ group spent less time in locomotion compared to the CTL group ( $p<0.001$ ) at 29 days of age, and at 45 days of age the difference between the groups persisted $(\mathrm{p}<0.05)$. No differences were observed between the CP and CTL groups regarding the number of quadrants crossed in the open field at 29 and 45 days of age (Table I).

Regarding exploratory behavior, the frequency of rearing in the $\mathrm{CP}$ group was only lower when compared to the CTL group at 29 days of age $(\mathrm{p}<0.01)$. There were no differences between the experimental groups regarding the frequency of grooming behavior at either of the two evaluations.

Table I. Locomotor variables of the animals from the CTL and CP groups evaluated in the open field at 29 and 45 days of age.

\begin{tabular}{lcccc}
\hline Variables & CTL & CP & CTL & CP \\
$(\mathrm{n}=10)$ & P29 & P29 & P45 & P45 \\
\hline Locomotion time (seconds) & $94.1 \pm 15.8$ & $55.9 \pm 24.2^{* * *}$ & $67.3 \pm 16.8$ & $49.2 \pm 21.6^{*}$ \\
Number of quadrant crossings & $96.1 \pm 22.1$ & $85.2 \pm 35.9$ & $72.2 \pm 30.6$ & $69.9 \pm 39.2$ \\
Grooming frequency & $2.5 \pm 1.0$ & $2.7 \pm 0.8$ & $2.3 \pm 0.9$ & $3.1 \pm 1.3$ \\
Number of rearings & $37.0 \pm 7.6$ & $21.0 \pm 12.5^{* *}$ & $21.3 \pm 12.6$ & $22.3 \pm 12.3$ \\
\hline
\end{tabular}

Values expressed as mean \pm standard deviation. Grooming frequency: Mann Whitney test. Other parameters: Student's t-test. $*$ Represents $\mathrm{p}<0.05, * *$ Represents $\mathrm{p}<0.01, * * *$ Represents $\mathrm{p}<0.001$. 

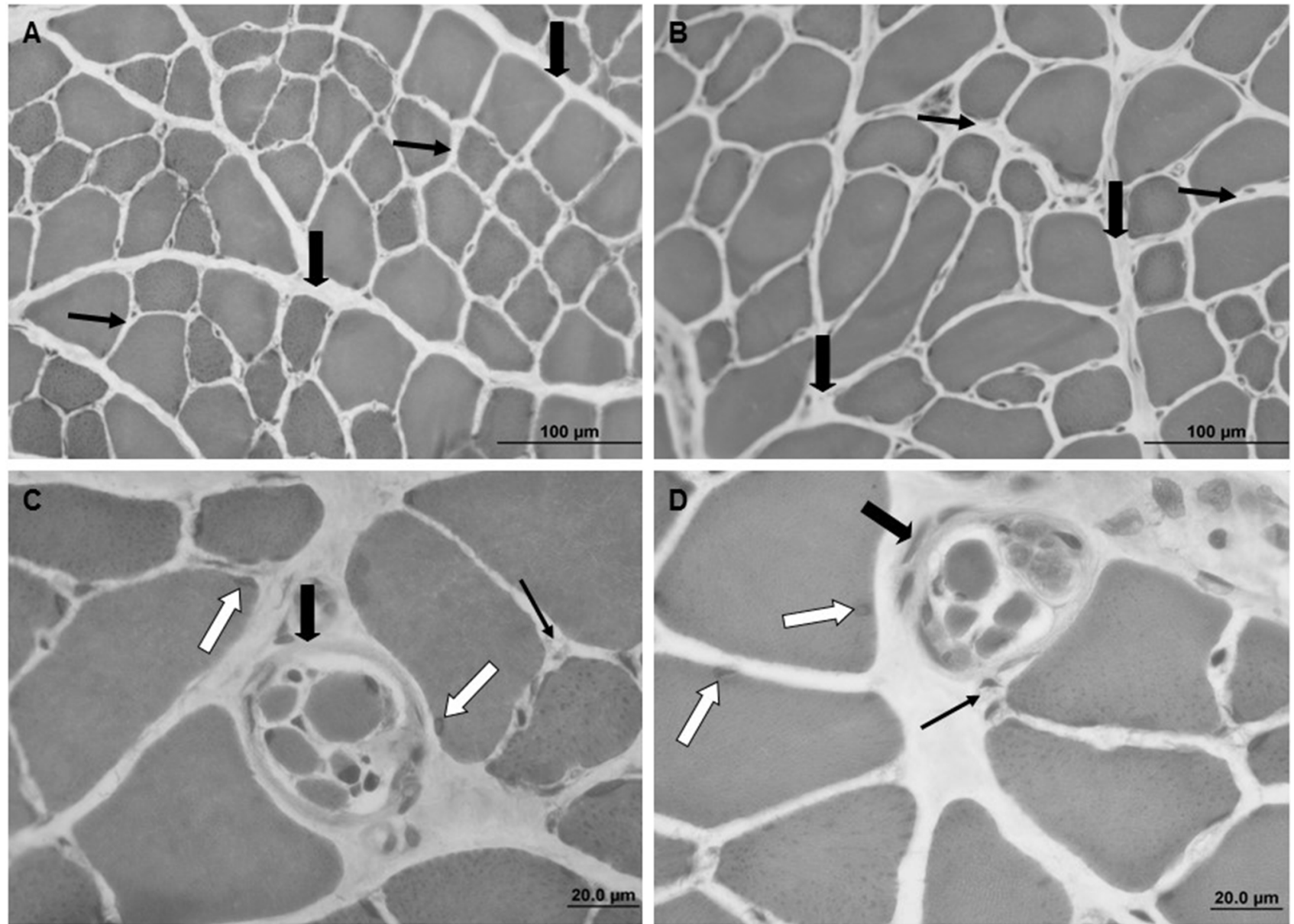

Fig. 1. Photomicrographs of EDL muscle fibers from Wistar rats at 48 days of age. Cross section, HE staining. CTL (A and C) and CP (B and D) groups. A and B: Note the perimysium (thick arrows), endomysium (long arrows). C and D: Note the peripheral nuclei (white arrows), muscle spindle capsule (thick arrows), intrafusal fibers (arrow heads) and capillaries (thin arrows).

Anthropometric variables. At 48 days of age, the body weight of the animals in the CP group was $16 \%$ lower in relation to the CTL group ( $\mathrm{p}<0.001$ ). The animals in the $\mathrm{CP}$ group also presented a $16 \%$ reduction in weight $(\mathrm{p}$ $<0.01$ ) and a $15 \%$ reduction in EDL muscle length (p $<0.01$ ) when compared to the CTL group (Table II).

Morphological and morphometric analysis of the muscle fibers. The muscle fibers of the EDL muscle from the two experimental groups had a normal morphological aspect,

Table II. Body weight and EDL muscle weight and length in rats at 48 days of age.

\begin{tabular}{lcc}
\hline \multicolumn{1}{c}{ Variables $(\mathbf{n}=\mathbf{1 0})$} & CTL & CP \\
\hline Body weight $(\mathrm{g})$ & $197 \pm 6.8$ & $165 \pm 17.2^{* * *}$ \\
Muscle weight $(\mathrm{g})$ & $0.08 \pm 0.01$ & $0.07 \pm 0.01^{* *}$ \\
Muscle length $(\mathrm{mm})$ & $21.4 \pm 3.1$ & $18.2 \pm 2.1^{* *}$ \\
\hline
\end{tabular}

Values expressed as mean \pm standard deviation. Animal weight: Mann Whitney test. Other parameters: Student's t-test. ${ }^{* *}$ Represents $\mathrm{p}<0.01$, *** Represents $\mathrm{p}<0.001$. regular diameter, a polygonal shape with rounded angles and peripheral nuclei in the subsarcolemmal position (Figs. 1AB). The fibers were arranged in fascicles surrounded by the perimysium, with each fiber being surrounded by endomysium. Vessels and nerves were present in the connective tissue of the muscle. The muscle spindles in the EDL muscle were observed in the two studied groups and were found to have a normal organizational pattern, that is, smaller and thinner intrafusal fibers, surrounded by a connective tissue capsule (Figs. 1C-D).

Regarding morphometry, there was an increase in the number of peripheral nuclei in the $\mathrm{CP}$ group compared to the CTL group $(\mathrm{p}=0.034)$, while the number of muscle fibers was similar between the studied groups (Figs. 1A-B) (Table III). Thus, the core/fiber ratio was $27 \%$ higher in the $\mathrm{CP}$ group compared to the CTL group ( $\mathrm{p}<0.01)$. There was also an increase of $23 \%$ in the capillary/fiber ratio (Table III). In the $\mathrm{CP}$ group, the muscle spindle area and the mean cross-sectional area of the intrafusal fibers were $26 \%$ smaller 
Table III. Morphometry of the EDL muscle and muscle spindles from the CTL and CP groups at 48 days of age.

\begin{tabular}{lcc}
\hline Variables $(\mathrm{n}=8)$ & CTL & CP \\
\hline Number of peripheral nuclei & $869.3 \pm 82.6$ & $1060 \pm 214.7^{*}$ \\
Number of muscular fibers & $492.4 \pm 60.4$ & $472.9 \pm 79.8$ \\
Nuclei/fiber & $1.8 \pm 0.3$ & $2.2 \pm 0.3^{* *}$ \\
Capillary/fiber & $2.2 \pm 0.2$ & $2.7 \pm 0.3^{* *}$ \\
Largest diameter of muscle spindles $(\mu \mathrm{m})$ & $74.5 \pm 16.1$ & $82.5 \pm 40.3$ \\
Cross-sectional area of muscle spindles $\left(\mu \mathrm{m}^{2}\right)$ & $3443 \pm 1264$ & $2541 \pm 1603^{*}$ \\
Number of intrafusal fibers & $4.1 \pm 0.4$ & $4.3 \pm 0.7$ \\
Cross-sectional area of intrafusal fibers $\left(\mu \mathrm{m}^{2}\right)$ & $182.4 \pm 56.3$ & $135.3 \pm 35.2^{*}$ \\
Muscle spindle capsule thickness $(\mu \mathrm{m})$ & $20.3 \pm 13.4$ & $19.4 \pm 15.2$
\end{tabular}

Values expressed as mean \pm standard deviation. * Represents $p<0.05$. ** Represents $p<0.01$. Number of peripheral nuclei, Number of muscle fibers, Nuclei/fiber, Capillary/fiber and Largest diameter of muscle spindles: Student t-test. Other parameters: Mann Whitney test.

when compared to the CTL group (Figs. 1C-D) (Table III). However, there no significant difference between the groups in terms of the largest diameter of the muscle spindle, number of intrafusal fibers, or muscle spindle capsule thickness. Intramuscular collagen showed a $34 \%$ increase in the CP group compared to the CTL group $(\mathrm{p}=0.009)$ (Fig. 2).

The histoenzymological analysis permitted the muscle fibers from the CP and CTL groups to be characterized as types I, IIA and IIB (Figs. 3A-B). There was a significant increase in the cross-sectional area of the type IIB fibers from the $\mathrm{CP}$ group compared to CTL (two-way ANOVA showed significant interaction effect $(\mathrm{F}(2.42)=3.35 ; \mathrm{p}=0.04)$, for the group $(\mathrm{F}(1.42)=6.88 ; \mathrm{p}=0.01)$ and for the fibers $(\mathrm{F}(2.42)$ $=187 ; \mathrm{p}<0.001)$. Regarding the other fiber types, there were no differences between the groups (Fig. 3C). Similarly, there was no significant difference between the groups in terms of count of the three identified muscle fiber types (Two-way ANOVA showed a significant effect for the fibers $(\mathrm{F}(2.42)=$ 13.1; $\mathrm{p}<0.001)$, whereas no effect was observed for the interaction $(\mathrm{F}(2.42)=1.88 ; \mathrm{p}=0.16)$ and for the group $(\mathrm{F}(1.42)$ $=0.11 ; \mathrm{p}=0.74)($ Fig. 3D).

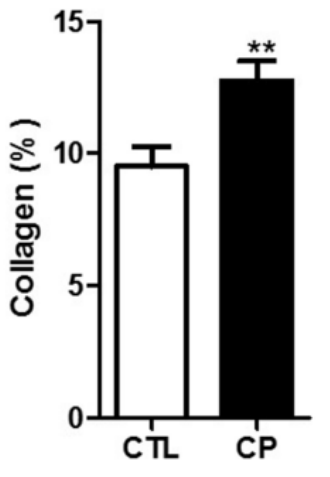

Fig. 2. Percentage of the intramuscular collagen quantification in the EDL muscle of Wistar rats at 48 days of age from the CTL and $\mathrm{CP}$ groups. Values expressed as mean \pm standard deviation. **Represents p <0.01; Student's t-test.
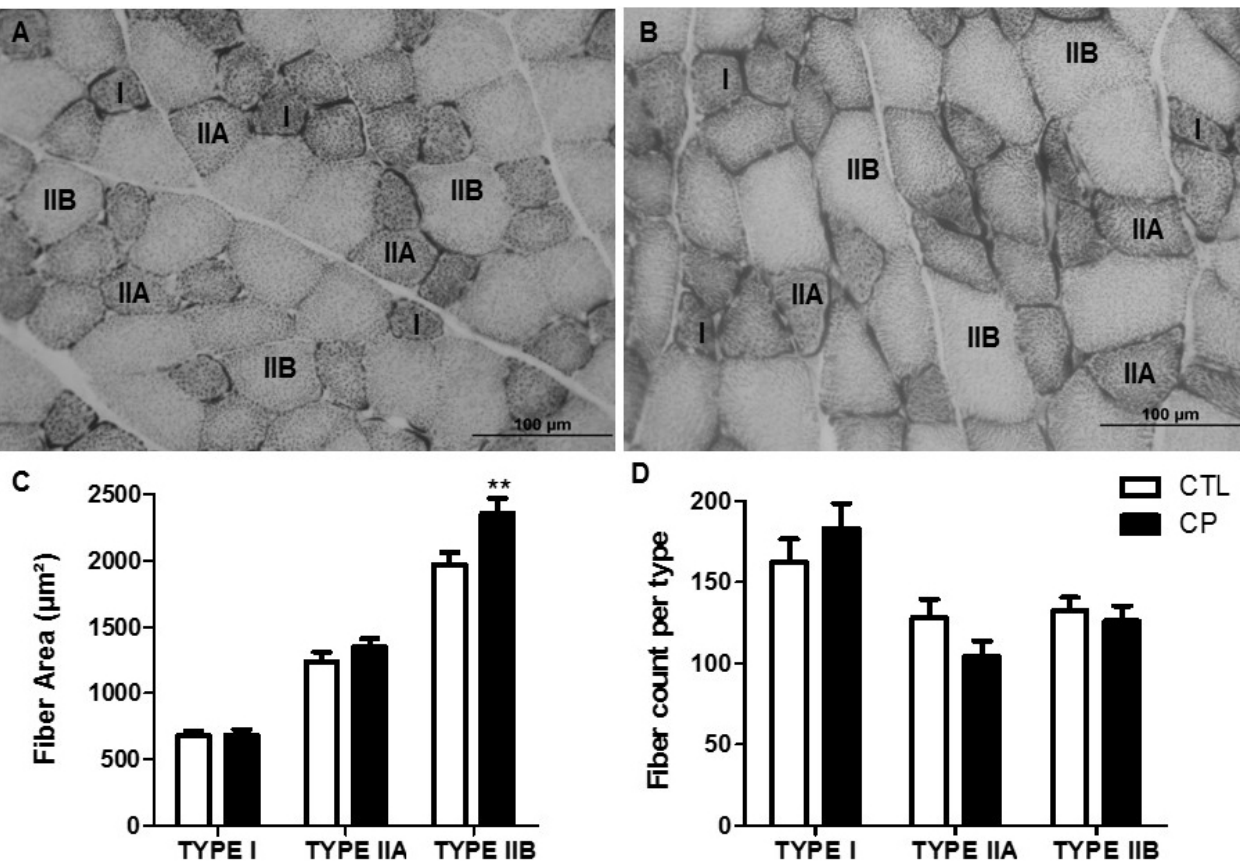

Fig. 3. Photomicrographs of the NADH-TR reaction in the EDL muscle fibers of Wistar rats at 48 days of age. Cross section. A and B: Morphology of the different types of muscle fibers in the CTL and CP groups, respectively. Fibers with small diameter (I), intermediate diameter (IIA) and large diameter (IIB). C: Cross-sectional area of the different types of muscle fibers observed in the EDL muscle in rats from the CP and CTL groups. D: Number of muscle fibers of types I, IIA and IIB observed in the EDL muscle of rats from the CP and CTL groups. Values expressed as mean \pm standard deviation. Two-way ANOVA, post-hoc Bonferroni test. 
Ultrastructural analysis of the EDL muscle. The morphology of the EDL muscle from the CTL group exhibited sarcoplasm with the presence of well-defined myofibrils and an organized Z-line (Fig. 4A). In the animals from the $\mathrm{CP}$ group, there was dissolution and disorganization of the Z-line in several regions $(\mathrm{p}<0.05)$ and rarefied or loosely arranged myofibrils ( $p<0.001$, Figs. $4 B$ and $4 C$ ) were observed.
Morphological and morphometric analysis of NMJs. The NMJs from the CP and CTL groups were polymorphic, round, oval and elliptical in shape (Figs. 5A-B). The morphometric analysis showed an increase in the area $(22 \%, \mathrm{p}<0.001)$ (Fig. $5 \mathrm{C})$ and in the larger diameter $(11 \%, \mathrm{p}<0.05)$ of the NMJs from the CP group compared to the CTL group (Fig. 5D). There was no significant difference between the groups studied in relation to the smallest diameter of the NMJs (Fig. 5E).
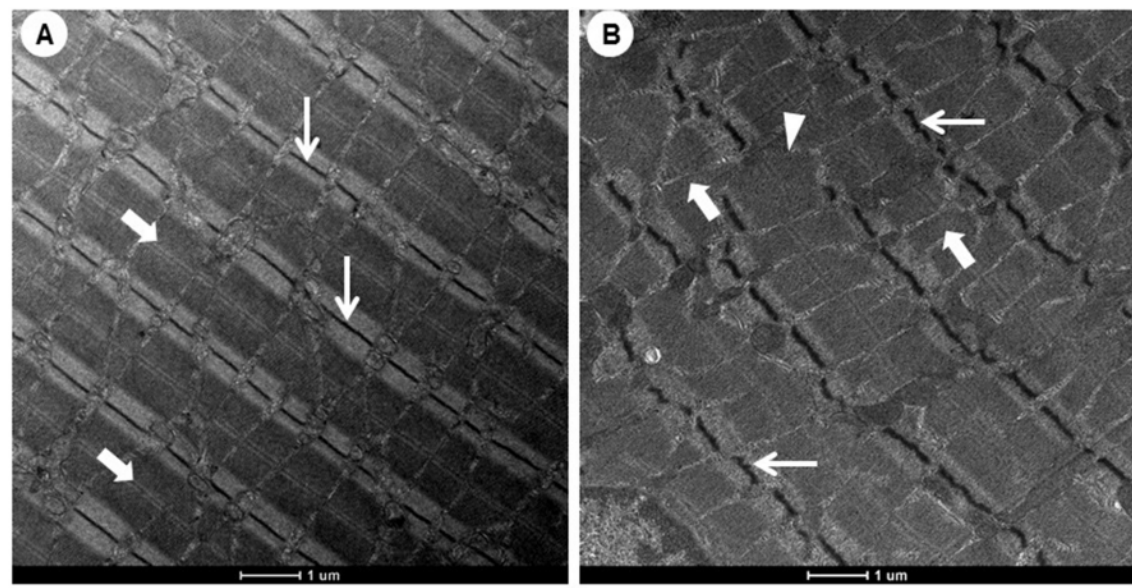

C

\begin{tabular}{|c|c|c|}
\hline Observations & CTL Group & CP Group \\
\hline Z Line disorganization (\%) & $18,3 \pm 10,4$ & $67,25 \pm 8,3^{\star \star \star}$ \\
\hline$Z$ line dissolution (\%) & $5,0 \pm 5,0$ & $23,8 \pm 14,7^{\star}$ \\
\hline Myofibrillar disruption (\%) & $9,0 \pm 9,6$ & $25,8 \pm 8,5^{\star}$ \\
\hline
\end{tabular}
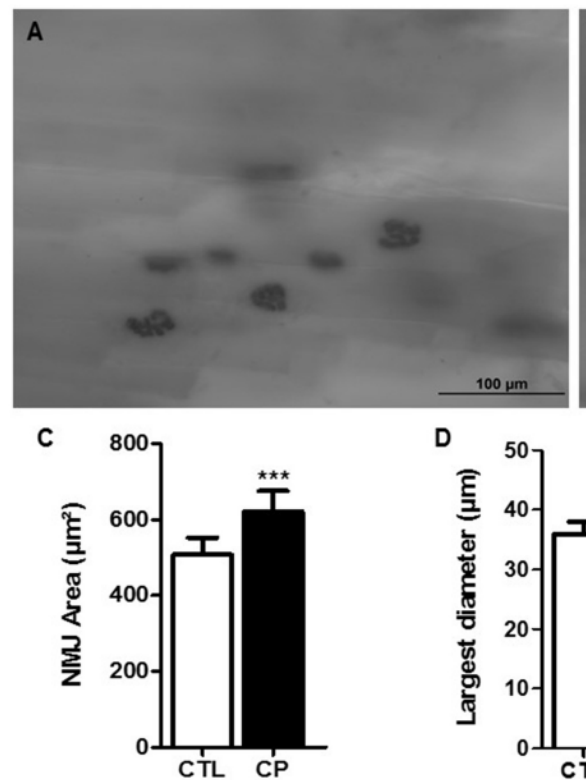

D
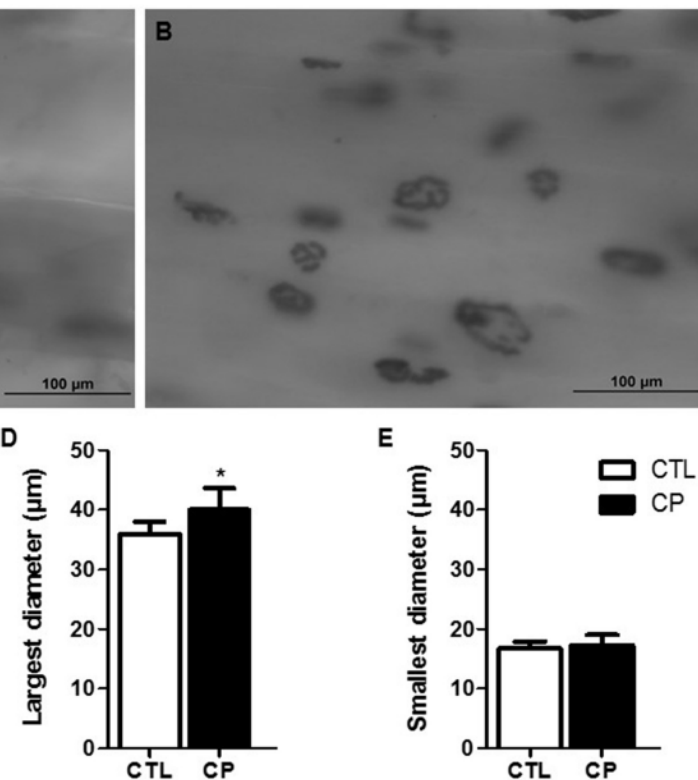

E

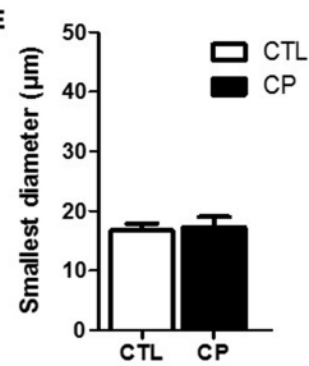

Fig. 4. Transmission electromicrographs of 48-day-old rat EDL muscle in longitudinal section. A: CTL Group Organized myofibrils (short arrow) and alignment of the $\mathrm{Z}$ line (long arrow). B: CP Group Myofibrils, sparse or loosely arranged (short arrow), disorganization (long arrow) and dissolution of the $\mathrm{Z}$ line (arrowhead). Bar $=1 \mathrm{~mm}$. C: Values expressed as mean \pm standard deviation. Z-line dissolution: Mann Whitney test. Other parameters: Student's t-test.
Fig. 5. Photomicrographs of the NMJs observed in the EDL muscle of Wistar rats at 48 days of age. Longitudinal section, Nonspecific esterase reaction. A and B: Morphological characteristics of the NMJs of the animals from the CTL and CP groups. C, D and $\mathrm{E}$ : Area, largest diameter and smallest diameter of the NMJs of the animals from the CTL and CP groups, respectively. Values expressed as mean \pm standard deviation. $* * *$ Represents $\mathrm{p}$ $<0.001$; *Represents $\mathrm{p}<0.05$. Smallest diameter of NMJs: Mann Whitney test. Other parameters: Student's t-test. 


\section{DISCUSSION}

In the present study, the animals from the $\mathrm{CP}$ group spent less time locomotion during the open field test when compared to the CTL group at 29 and 45 days of age. There was no improvement in this parameter even after the removal of the sensorimotor restriction. Regarding the number of quadrants crossed by the animals during that test, the $\mathrm{CP}$ and CTL groups were similar at 29 and 45 days of age. Sensorimotor restraint causes intrinsic muscle disruption due to disuse (Coq et al.) and animals submitted to this procedure have difficulty discharging the plantar weight during the support phase, which may compromise gait and other motor skills (Strata et al., 2004). However, the result might be related to the fact the animals from the $\mathrm{CP}$ group compensated for their deficits by greater use of the thoracic limbs. Stigger et al. (2013), also found no difference in the distance covered in the open field test at 29 days of age. Grooming frequency was also similar between the $\mathrm{CP}$ and CTL groups at both evaluations. Although LPS injections and perinatal anoxia are known to be able to cause damage to the white matter and disorganization of M1 (Strata et al.), these two insults may not have affected thoracic limb motor control in the $\mathrm{CP}$ group. As for the number of rearings, a behavior that requires strength and control of the pelvic limbs, there was a reduction in the $\mathrm{CP}$ group when compared to the CTL group at 29 days. Thus, sensorimotor restriction would seem to play a fundamental role in inducing motor alterations in the hind limbs. Spontaneous motor activity is known to be essential for the development of the corticospinal tract (Clowry, 2007). Motor experiments reinforce and refine synaptic connectivity, favor myelination of the corticospinal tract and maturation of the motor unit and reflex circuits. Interventions that impair the performance of movements during the development of locomotion, such as sensorimotor restraint, may disturb the establishment of connections within the motor circuit (Clowry), leading to functional impairment.

The body weight of the animals from the $\mathrm{CP}$ group was significantly lower than that of the CTL group. In humans, low birth weight is one of the main risk factors associated with CP (Johnston \& Hoon, 2006). Marques et al. (2014), using LPS injections, perinatal anoxia and sensorimotor restriction to induce $\mathrm{CP}$, also observed reduced body weight in the animals and attributed the finding to a decrease in bone mineral density due to lack of weight discharge. In this study, a reduction in the length of the EDL muscle was also observed in the $\mathrm{CP}$ group. Longitudinal muscle growth occurs in the first four to six postnatal weeks in rats (Dayanidhi \& Lieber, 2014). The lack of longitudinal growth of skeletal muscle in patients with $\mathrm{CP}$ leads to muscle contractures, long bone twitches and early joint degeneration (Kerr Graham \& Selber). Again, this animal model of CP reproduced one of the characteristic clinical findings of this pathology, muscular shortening.

In the present study, there was an increase in the number of peripheral nuclei and in the core/fiber ratio in the $\mathrm{CP}$ group. Muscle fibers that have a greater number of nuclei generally have a larger cross-sectional area, but in certain circumstances, these parameters may change independently of one another (Roy et al., 1999). The CP group was also found to have a higher capillary/muscle fiber ratio associated with hypertrophy of type IIB fibers in the EDL muscle. Increased capillary density, resistance, and hypertrophy of muscle fibers are some of the changes seen in target muscles of continuous muscular activation due to spasticity (Foran et al., 2005). In this study, an increase in intramuscular collagen was observed. Neuronal activity regulates the synthesis of collagen and in spastic muscles the neuronal stimulation is intensified (Booth et al., 2001). Gagliano et al. (2013) observed that patients with spastic CP also have increased collagen in the tendons. These muscular alterations lead to muscle stiffness and reduced function (Coq et al.). Spasticity-induced fibrosis directly limits muscle length growth (Booth et al.), which together forms a mechanical barrier to muscle regeneration (Chen \& Li, 2009).

This is the first time the characteristics of muscle with a predominance of type II fibers following the induction of this animal model of CP have been observed. In an earlier study, Marcuzzo et al. (2008) showed that the sensorimotor restriction alone or associated with perinatal anoxia causes atrophy of the soleus muscle of rats, which was improved after treadmill training. Stigger et al. $(2011,2013)$ noted a reduction in the cross-sectional area of the soleus and anterior tibial muscle fibers using the same $\mathrm{CP}$ model. The predominance of fibers within a muscle will cause it to have different biochemical and structural properties (AlmeidaSilveira et al., 1994), which promote varied responses to certain insults (Mercier et al., 1999).

Regarding the muscle spindles, the absence of weight discharge is known to be able to reduce the cross-section area of the intrafusal fibers, decrease the diameter of the equatorial region and fragment the nerve endings (Zhu et al., 2008). In the present study, there was a decrease in the muscle spindle area and the cross-sectional area of the intrafusal fibers in the CP group. Apparently, the period between removal of the sensorimotor restraint and the euthanasia of the animals was insufficient to repair the muscle spindle structure, although the intrafusal fibers presented high concentrations of satellite cells and a smaller myonuclear domain, which favor growth, regeneration and repair (Zhu et al.). 
The ultrastructural study of the EDL muscle showed alterations such as myofibrillar disruption and Z-line disorganization and dissolution in the animals from the $\mathrm{CP}$ group. Studies using electron microscopy in animal models of CP are scarce and are generally conducted through biopsies of individuals with this pathology. Patients with myofibrillar myopathies exhibit ultrastructural alterations that are typically focal. Some regions contain normal sarcomeres alternating with areas of pronounced myofibrillar disruption (Zhu et al.). This animal model reproduced focal ultrastructural changes similar to those found in patients with CP. According to Marbini et al. (2002), myofibrillar disruption is found in all cases, which is associated with Zline disorganization and a consequent loss of the striation that is characteristic of the skeletal muscle.

The animals from the CP group presented an increase in the area and in the largest diameter of the NMJs when compared to the CTL group. NMJs are structures that can remodel themselves according to the functional demands (Pratt et al., 2013). Conditions such as disuse, neuromuscular disorders and aging lead to muscle weakness, causing NMJs to lose functionality in the most affected regions (Rudolf et al., 2016). In this study, the disuse caused by the sensorimotor restriction may have caused the longitudinal lengthening of the nerve terminals in order to reinforce synaptic transmission and maintain muscle function (Fahim \& Robbins, 1986).

The association of LPS injections, perinatal anoxia and sensorimotor restraint produced lasting effects on the function and structure of the muscular system, as shown by the reduction in rearing frequency and in muscle length. There were increases in the nuclei/fiber ratio, capillary/fiber ratio, type IIB fiber muscle hypertrophy and intramuscular collagen, which are findings commonly found in patients with spastic $\mathrm{CP}$. The morphological alterations found in the muscle spindle may affect posture maintenance and movement coordination. The ultrastructural study of the EDL muscle showed alterations similar to those found in biopsies of patients with CP. However, the alterations to the NMJs caused by the animal model of $\mathrm{CP}$ constitute new discoveries, which require further investigation.

This animal model proved to be a useful means to understand the pathophysiology of this clinical condition. It is suggested that new studies be performed with evaluations at different periods, that is, during sensorimotor restriction and soon after its removal. The need for such studies became evident sue to the fact that immobilization in the developmental period of locomotion aggravated the repercussions of the clinical condition. Given this, this experimental model could be an important tool to check the efficacy of early-start rehabilitation programs.
COVATTI, C.; UlSENhEIMER, B. H.; BURATTI, P.; CENTENARO, L. A.; GUIMARÃES, A. T. B.; BRANCALHÃO, R. M. C. \& TORREJAIS, M. M. Evaluación de un modelo animal de parálisis cerebral: los efectos sobre la morfología del músculo extensor largo de los dedos. Int. J. Morphol., 36(3):886-894, 2018.

RESUMEN: La parálisis cerebral (PC) se refiere a la encefalopatía crónica infantil. El objetivo de este estudio fue verificar los efectos del modelo PC que combina la exposición prenatal a LPS, la anoxia perinatal y la restricción sensitivo-motora en el músculo extensor largo de los dedos (MELD). Se separaron las crías de ratas Wistar machos: a) Control: crías de madres inyectadas con solución salina durante la preñez y b) Parálisis cerebral: crías de madres inyectadas con LPS durante la preñez y sometidas a anoxia perinatal y restricción sensitivo-motora. El grupo PC presentó hipertrofia en las fibras tipo IIB y aumento de la relación núcleo / fibra y capilar / fibra. Las fibras intrafusales del grupo PC presentaron un $26 \%$ de atrofia en el área de la sección transversal y el volumen de colágeno intramuscular aumentó un $34 \%$. El grupo PC mostró disrupción miofibrilar y desorganización de la línea $\mathrm{Z}$ y los NMJ presentaron aumentos de $22 \%$ en el área. Este modelo animal de PC produce déficit motores y alteraciones macro y microscópicas y cambios en la ultraestructura del MELD.

PALABRAS CLAVE: Parálisis cerebral; Rata; Músculo extensor largo de los dedos; Morfología; Morfometría.

\section{REFERENCES}

Almeida-Silveira, M. I.; Pérot, C.; Pousson, M. \& Goubel, F. Effects of stretch-shortening cycle training on mechanical properties and fibre type transition in the rat soleus muscle. Pflugers Arch., 427(3-4):28994, 1994.

Bax, M.; Goldstein, M.; Rosenbaum, P.; Leviton, A.; Paneth, N.; Dan, B.; Jacobsson, B.; Damiano, D. \& Executive Committee for the Definition of Cerebral Palsy. Proposed definition and classification of cerebral palsy, April 2005. Dev. Med. Child. Neurol., 47(8):571-6, 2005.

Booth, C. M.; Cortina-Borja, M. J. \& Theologis, T. N. Collagen accumulation in muscles of children with cerebral palsy and correlation with severity of spasticity. Dev. Med. Child. Neurol., 43(5):314-20, 2001.

Chen, X. \& Li, Y. Role of matrix metalloproteinases in skeletal muscle: migration, differentiation, regeneration and fibrosis. Cell Adh. Migr., 3(4):337-41, 2009.

Clowry, G. J. The dependence of spinal cord development on corticospinal input and its significance in understanding and treating spastic cerebral palsy. Neurosci. Biobehav. Rev., 31(8):1114-24, 2007.

Coq, J. O.; Strata, F.; Russier, M.; Safadi, F. F.; Merzenich, M. M.; Byl, N. N. \& Barbe, M. F. Impact of neonatal asphyxia and hind limb immobilization on musculoskeletal tissues and S1 map organization: implications for cerebral palsy. Exp. Neurol., 210(1):95-108, 2008.

Dayanidhi, S. \& Lieber, R. L. Skeletal muscle satellite cells: mediators of muscle growth during development and implications for developmental disorders. Muscle Nerve, 50(5):723-32, 2014.

Fahim, M. A. \& Robbins, N. Remodelling of the neuromuscular junction after subtotal disuse. Brain Res., 383(1-2):353-6, 1986.

Foran, J. R.; Steinman, S.; Barash, I.; Chambers, H. G. \& Lieber, R. L. Structural and mechanical alterations in spastic skeletal muscle. Dev. Med. Child. Neurol., 47(10):713-7, 2005. 
COVATTI, C.; ULSENHEIMER, B. H.; BURATTI, P.; CENTENARO, L. A.; GUIMARÃES, A. T. B.; BRANCALHÃO, R. M. C. \& TORREJAIS, M. M. An evaluation of an animal model of cerebral palsy: The effects on the morphology of the extensor digitorum longus muscle. Int. J. Morphol., 36(3):886-894, 2018.

Gagliano, N.; Menon, A.; Martinelli, C.; Pettinari, L.; Panou, A.; Milzani, A.; Dalle-Donne, I. \& Portinaro, N. M. Tendon structure and extracellular matrix components are affected by spasticity in cerebral palsy patients. Muscles Ligaments Tendons J., 3(1):42-50, 2013.

Johnston, M. V. \& Hoon, A. H. Jr. Cerebral palsy. Neuromolecular Med., $8(4): 435-50,2006$.

Kerr Graham, H. \& Selber, P. Musculoskeletal aspects of cerebral palsy. $J$. Bone Joint Surg. Br., 85(2):157-66, 2003.

Mancini, M. C.; Fiúza, P. M.; Rebelo, J. M.; Magalhães, L. C.; Coelho, Z. A. C.; Paixão, M. L.; Gontijo, A. P. B. \& Fonseca, S. T. Comparação do desempenho de atividades funcionais em crianças com desenvolvimento normal e crianças com paralisia cerebral. Arq. Neuropsiquiatr., 60(2-B):446-452, 2002.

Marbini, A.; Ferrari, A.; Cioni, G.; Bellanova, M. F.; Fusco, C. \& Gemignani, F. Immunohistochemical study of muscle biopsy in children with cerebral palsy. Brain Dev., 24(2):63-6, 2002.

Marcuzzo, S.; Dutra, M. F.; Stigger, F.; do Nascimento, P. S.; Ilha, J.; KalilGaspar, P. I. \& Achaval, M. Beneficial effects of treadmill training in a cerebral palsy-like rodent model: walking pattern and soleus quantitative histology. Brain Res., 1222:129-40, 2008.

Marques, M. R.; Stigger, F.; Segabinazi, E.; Augustin, O. A.; Barbosa, S.; Piazza, F. V.; Achaval, M. \& Marcuzzo, S. Beneficial effects of early environmental enrichment on motor development and spinal cord plasticity in a rat model of cerebral palsy. Behav. Brain Res., 263:14957, 2014

Mercier, C.; Jobin, J.; Lépine, C. \& Simard, C. Effects of hindlimb suspension on contractile properties of young and old rat muscles and the impact of electrical stimulation on the recovery process. Mech. Ageing Dev., 106(3):305-20, 1999.

Pratt, S. J.; Shah, S. B.; Ward, C. W.; Inacio, M. P.; Stains, J. P. \& Lovering, R. M. Effects of in vivo injury on the neuromuscular junction in healthy and dystrophic muscles. J. Physiol., 591(2):559-70, 2013.

Rotta, N. T. Paralisia cerebral, novas perspectivas terapêuticas. J. Pediatr, 78 Suppl. 1:S48-S54, 2002.

Roy, R. R.; Monke, S. R.; Allen, D. L. \& Edgerton, V. R. Modulation of myonuclear number in functionally overloaded and exercised rat plantaris fibers. J. Appl. Physiol. (1985), 87(2):634-642, 1999.

Rudolf, R.; Deschenes, M. R. \& Sandri, M. Neuromuscular junction degeneration in muscle wasting. Curr. Opin. Clin. Nutr. Metab. Care., 19(3):177-81, 2016

Stigger, F.; Felizzola, A. L.; Kronbauer, G. A.; Couto, G. K.; Achaval, M. \& Marcuzzo, S. Effects of fetal exposure to lipopolysaccharide, perinatal anoxia and sensorimotor restriction on motor skills and musculoskeletal tissue: implications for an animal model of cerebral palsy. Exp. Neurol., 228(2):183-91, 2011.

Stigger, F.; Lovatel, G.; Marques, M.; Bertoldi, K.; Moysés, F.; Elsner, V.; Siqueira, I. R.; Achaval, M. \& Marcuzzo, S. Inflammatory response and oxidative stress in developing rat brain and its consequences on motor behavior following maternal administration of LPS and perinatal anoxia. Int. J. Dev. Neurosci., 31(8):820-7, 2013.

Strata, F.; Coq, J. O.; Byl, N. \& Merzenich, M. M. Effects of sensorimotor restriction and anoxia on gait and motor cortex organization: implications for a rodent model of cerebral palsy. Neuroscience, 129(1):141-56, 2004.

Zhu, Y.; Fan, X.; Li, X.; Wu, S.; Zhang, H. \& Yu, L. Effect of hindlimb unloading on resting intracellular calcium in intrafusal fibers and rampand-hold stretches evoked responsiveness of soleus muscle spindles in conscious rats. Neurosci. Lett., 442(3):169-73, 2008.

\author{
Corresponding author: \\ Prof. Dr. Marcia Miranda Torrejais \\ Centro de Ciências Médicas e Farmacêuticas \\ Universidade Estadual do Oeste do Paraná \\ UNIOESTE - Campus de Cascavel. 85814-110 \\ Cascavel - Paraná \\ BRAZIL
}

E-mail: mmtorrejais@yahoo.com.br

Received: 10-01-2018

Accepted: 12-04-2018 